\title{
Argumentos anticirenaicos en el programa cultural de la República de Platón
}

\section{[Anti-Cyrenaic Arguments in Plato's Republic Cultural Program]}

\author{
ClAudia MÁRSICO \\ Universidad de Buenos Aires \\ Consejo Nacional de Investigaciones Científicas y Técnicas \\ Academia Nacional de Ciencias de Buenos Aires \\ claudiamarsico@gmail.com
}

\begin{abstract}
Resumen: Platón proyecta en la República un programa cultural que supone la redefinición del papel de la poesía tradicional en razón de su asociación con los regímenes democrático y tiránico. Esto, según pretendo mostrar, puede vincularse de manera legítima con la polémica anticirenaica de Platón contra Aristipo. Para ello, por un lado, exploraré los rasgos del biotipo tiránico y su régimen concomitante en la República VIII-IX y, por otro, analizaré sus vínculos con los planteamientos anticirenaicos en el Gorgias. Este examen permitirá ofrecer claves de análisis para dos pasajes muy discutidos de la República IX: el símil del ascensor y el número del tirano, que cobran una nueva luz a partir de la consideración de esta polémica intrasocrática.
\end{abstract}

Palabras clave: psicología, política, Aristipo, poesía, tiranía

\begin{abstract}
Plato put forward in Republic a cultural program which implies the redefinition of the role of traditional poetry due to its association with the democratic and tyrannical regimes. I intend to show that this point is connected with the anti-cyrenaic arguments that Plato raises against Aristippus. On the one hand, I will study the features of the tyrannical biotype and its correspondent regime in Republic VIII-IX, and, on the other, I will analyze its links with the anti-cyrenaic arguments in Gorgias. This exam will allow us to offer some clues to better understand two widely debated passages in Republic IX: the analogy of the lift and the tyrant's number. Both acquire a new perspective when this intra-socratic polemic is taken into account.
\end{abstract}

Key words: psychology, politics, Aristippus, poetry, tyranny

Las exploraciones platónicas hacen referencia a la poesía de modos muy variados, lo cual no sorprende en un contexto en el que la filosofía, en proceso de instaurarse como discurso autónomo, necesitaba diferenciarse de los formatos preexistentes. ${ }^{1}$ En el marco de una propuesta cultural integral que pretende que la nueva disciplina figure en un primer plano y oficie de rectora en los terrenos epistémico y político, la crítica de la poesía se vuelve prioritaria. ${ }^{2}$ Por otra parte, en los mecanismos para justificar su propuesta Platón apela a su asociación

${ }^{1}$ Sobre este proceso, véase Nightingale 1995.

${ }^{2}$ Véanse Gaiser 1984, Cerri 1991, Rowe 2007, Halliwell 2011 y Allen 2010.

Revista de Filosofía Diánoia, vol. 64, no. 83 (noviembre de 2019-abril de 2020): pp. 3-26 e-ISSN: 1870-4913 • DOI: https://doi.org/10.22201/iifs.18704913e.2019.83.1716 
con líneas rivales que resultan así impugnadas en este mismo proceso. La combinación de ambos elementos, que no siempre se tiene en cuenta, ilumina escorzos relevantes del clima teórico de la época clásica y ofrece una asociación entre poesía tradicional y tiranía que legitima la impugnación de la autoridad simbólica de los poetas y permite objetar otras corrientes socráticas que, a juicio de Platón, no tienen elementos para contrarrestar los efectos negativos de esta práctica. ${ }^{3}$

En este trabajo me interesa concentrarme en el programa de política cultural de la República de Platón y su cuestionamiento de la tradición prestando atención a su polémica con la filosofía cirenaica. Para ello, primero, exploraré los rasgos del tipo tiránico y su régimen concomitante en la República VIII-IX, como base para analizar sus vínculos con los planteamientos anticirenaicos en el Gorgias. Esto permitirá ofrecer claves de análisis para dos pasajes muy discutidos de la República IX a la luz de esta polémica intrasocrática: el símil del ascensor y el número del tirano.

\section{El biotipo tiránico y la poesía tradicional}

Después de los análisis de los libros II y III y las alusiones mediante varios símiles —en especial el de la bestia (VI 493a6-d9) y el conjunto del sol, la línea y la caverna (VI 507a1-VII 521a8)_, ${ }^{4}$ la poesía reaparece en la República hacia el final de un largo planteamiento que se extiende entre VIII 543a1 y IX 592b6 e ilustra el paralelismo estructural entre lo anímico y lo político esbozado en II 368d1 y ss. ${ }^{5}$ Según esta idea, la psiquis tiene las mismas partes que la comunidad y el tipo de gobierno que adopte dependerá de qué parte predomine en los hombres que la componen. Se trata de un planteamiento biotípico, es decir, que identifica prototipos característicos de los individuos de una especie. En el caso platónico, el criterio biotípico se desprende de la clase

${ }^{3}$ Utilizo aquí la expresión "poesía tradicional" en un sentido amplio que abarca las sagas homéricas, el material hesiódico y la lírica, junto con las producciones del teatro más recientes, que forman la base cultural a la que apela Platón para caracterizar el tipo de ideario que la filosofía debería enfrentar para efectuar mejoras epistémicas y prácticas generales. No importa aquí, desde la perspectiva platónica, si hay poetas que hayan sostenido ideas políticas diferentes, sino que se pretende llamar la atención sobre una estructura que tiende a apoyar las estrategias de regímenes particulares.

${ }^{4}$ Sobre la poesía en estos pasajes, véanse Hunter 2012, pp. 86 y ss., y Mársico 2019.

${ }^{5}$ Véanse Ferrari 2005, pp. 59 y ss., y Divenosa y Mársico 2005, “Introducción”, secc. 5.1 .

Revista de Filosofía Diánoia, vol. 64, no. 83 (noviembre de 2019-abril de 2020)

e-ISSN: 1870-4913 • DOI: https://doi.org/10.22201/iifs.18704913e.2019.83.1716 


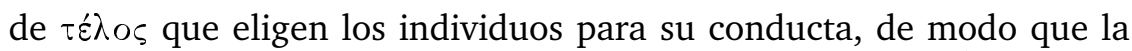
acumulación de opciones determina el destino comunitario. ${ }^{6}$

A la aristocracia corresponde una mayoría que se rige por la razón; a la timocracia una mayoría cuya parte más poderosa es la impulsiva (VIII $545 c 8-550 c 2$ ) y, si priman quienes obedecen a su parte apetitiva, la sociedad se encaminará hacia una oligarquía en la que el valor máximo es el dinero (VIII 550c4-555b2), una democracia en la que las escalas axiológicas se han perdido (VIII 555b3-561e7) o la pesadilla de una tiranía en la que los hombres dan rienda suelta a sus perversiones inconscientes en estado de vigilia (VIII 562a1-577b5). ${ }^{7}$ En última instancia, esta ordenación biotípica de acuerdo con la parte del alma que rige la conducta vuelve a la política un problema de psicología de masas.

Este esquema supone un detalle obliterado por las críticas tradicionales a Platón que subrayan su filiación elitista y, por lo tanto, antidemocrática. En rigor, la adopción del principio de paralelismo estructural entre el individuo y la sociedad lo aleja de confiar en vanguardias y compromete el sistema con una construcción colectiva que asegure un apoyo mayoritario al gobierno de los filósofos. ${ }^{8}$ La aristocracia platónica se apoya en un consenso alimentado por el programa cultural que pone en primer plano criterios epistémicos, éticos y políticos de prioridad de la virtud. Por ello, la tiranía es su opuesto, en la medida en que apunta a la concentración del poder y se despreocupa por la armonía entre todos los sectores de la ciudad (Boesche 2010, pp. 28-31).

Sin embargo, el caso de la tiranía resulta importante para el esquema general por otra razón que no es de oposición sino de similitud con el paradigma aristocrático. Igual que aquél, presenta el caso donde el biotipo predominante no elige distribuir el poder, sino cederlo voluntaria o involuntariamente a uno o varios líderes. El mecanismo es contrario al que se produce en la democracia donde, si bien sobre la falta de reconocimiento de derechos de la mayoría de mujeres, niños y metecos, se tiende al acceso igualitario entre los ciudadanos. Lo mismo sucede en

\footnotetext{
${ }^{6}$ Utilizo aquí la noción de "biotipo" en un sentido amplio para referirme a tipos de temperamento típicos. Si bien la noción tiene usos específicos en biología y se extendió al ámbito de las humanidades a partir de E. Kretschman y su Körperbau und Charakter. Untersuchungen zum Konstitutionsproblem und zur Lehre von den Temperamenten (Berlín, 1921), no implica que sea preciso adoptar su entorno teórico más que para referirnos a grupos específicos dentro de lo humano, a la manera en que lo plantea Platón en la obra que nos ocupa.

${ }^{7}$ Sobre esta clasificación, véanse Walsh 1962, pp. 3-16; Rosenstock 1994, pp. 363-390, y Ferrari 2005, pp. 65 y ss.

${ }^{8}$ Sobre las discusiones respecto del elitismo y el autoritarismo platónicos, véanse Klosko 1996 e Illarraga 2014.
}

Revista de Filosofía Diánoia, vol. 64, no. 83 (noviembre de 2019-abril de 2020) e-ISSN: 1870-4913 • DOI: https://doi.org/10.22201/iifs.18704913e.2019.83.1716 
la timocracia, caso en el cual el criterio de competencia generalizada establece un horizonte general de reglas de otorgamiento del poder. En cambio, en la aristocracia y la tiranía hay una cesión completa que puede resultar en el modelo más benigno o el más dañino.

Así, la pregunta que cabe es qué diferencia al rey filósofo del tirano, en especial cuando en la República VIII 566d8-e3 Platón deja claro que el régimen tiránico suele comenzar con obras bienhechoras de mejoramiento comunitario. En los casos de conversión filosófica, cuando el sistema de Calípolis no está todavía establecido, el sujeto que llega al poder podría propiciar tanto una monarquía o aristocracia como una tiranía. Si tenemos como parámetro el ascenso al poder de Dion en Siracusa apoyado por el entorno de Platón incluso con el envío de tropas, las convulsiones parecen inevitables e impiden pensar en una situación en la que sea fácil captar los rasgos que efectivamente acompañan al gobernante en ascenso. ${ }^{9}$ Dado que el tirano también se presentaría como el mejor gobernante posible, ¿cómo hacer para saber de cuál tipo de autoridad se trata?

La noción de tiranía que utiliza Platón es tributaria de una construcción deliberada que se remonta al siglo v, cuando la aristocracia alimentó la asociación entre bestialidad y gobiernos unipersonales de origen popular. Eso explica que Platón la considere una degradación de la democracia. ${ }^{10}$ Con este horizonte, la categoría de tiranía pretende describir un gobernante que ha abandonado toda institucionalidad y ejerce el poder con despotismo, lo opuesto del rey filósofo. Por regla general, como he dicho, comienza su gobierno con propuestas de mejoramiento comunitario (566d8-e3), pero progresivamente, para evitar la pérdida del poder, tiende a incrementar los actos de violencia (567b2-10).

Hasta aquí la diferencia entre el filósofo y el tirano no está clara. Platón no objeta el uso de la fuerza estatal, que sin duda está presente en la aristocracia filosófica para ordenar la ciudad e incluso puede volverse una presión para los filósofos si alguno no quisiera cumplir con sus obligaciones de gestión (VII 520c1-8). Sin embargo, la tiranía va más allá del orden y culmina de manera inevitable en actos sanguinarios y purgas (VIII 567c1-7), de modo que, al guiarse sólo por el

\footnotetext{
${ }^{9}$ Platón, Carta VII, 350; Carta III, 315e; Carta IV, 320 $\alpha$; Plutarco, Dion, 22; Cicerón, Tusc., I 25.53.

${ }^{10}$ Véanse Heródoto, V 44.1, VI 23.1, VII 161, y el contraste con Sófocles, Edipo Rey, 873, y los estudios Ehrenberg 1969, p. 162; McGlew 1993; Cawkwell 1995, pp. 73-86; Parker 1998, pp. 145-172; Raaflaub 2004, p. 255; Niquist 2013, pp. 31 y ss., e Illarraga, Mársico y Marzocca 2017.
}

Revista de Filosofía Diánoia, vol. 64, no. 83 (noviembre de 2019-abril de 2020) e-ISSN: 1870-4913 • DOI: https://doi.org/10.22201/iifs.18704913e.2019.83.1716 
comportamiento, es probable que el cuerpo social advierta demasiado tarde el tipo de gobernante que llegó al poder.

No obstante, en el contexto platónico hay un indicio claro que no implica conocer la mente del gobernante y sus propósitos personales para decidir sobre este asunto. La diferencia puede reconocerse en el programa cultural que defiende cada régimen. La aristocracia apela a recursos formativos generales para hacer perdurable el gobierno de base filosófica, mientras que la tiranía es el régimen que adopta con mayor vigor el imaginario tradicional hasta el punto de tomarlo como modelo y exacerbarlo. En efecto, para definir el biotipo de la ciudad tiranizada Platón recurre a la poesía y establece en forma explícita este vínculo en VIII 568a4-d9.

En este punto se trata de caracterizar la tiranía y su asociación con los poetas tradicionales aparece en primer plano. Entre muchas opciones posibles, el personaje de Sócrates elige a Eurípides y cita con sorna el verso "los tiranos son sabios por la compañía de los sabios", 11 que tiene el propósito de asociar ambos perfiles y pretende legitimar a quienes frecuentan las cortes. Para la época de redacción de la República, Platón había estado en esta situación durante el mecenazgo de Dionisio I en Siracusa y probablemente concibió a partir de los resultados nefastos del encuentro una idea sobre la diferencia entre buscar el apoyo de los gobernantes desde la poesía y hacerlo desde la filosofía. ${ }^{12}$ El modelo de $\pi \alpha p p \eta \sigma i \alpha$ que Platón asocia con esta última la convierte en un tipo discursivo poco apto para oídos acostumbrados a la lisonja. ${ }^{13}$

Desde esta perspectiva, el fracaso de Sócrates ante Alcibíades no sería un caso aislado, sino lo que tiende a suceder en los encuentros entre filósofos y políticos, estos últimos más cómodos siempre en compañía de los agentes culturales tradicionales. La memoria de los consejos de los sabios a los gobernantes queda aquí totalmente en entredicho y bajo la sospecha de oscura connivencia en pos de una política cultural que propicie la tiranía (Gray 2007, pp. 31-32). En efecto, se recuerda que Eurípides alaba la tiranía diciendo que "iguala a los dioses"14 y esto hacen también otros poetas, razón por la cual no hay que admitir-

${ }^{11}$ Atribuido también a Sófocles ( $f r .13$ Nauck) probablemente como referencia a la institución del patronato. Sobre este fenómeno en la Grecia clásica, véase Fraser 1972, pp. 305 y ss.

${ }^{12}$ Véanse Taylor 1926, pp. 7-21 y 371-374; Levy 1956; Riginos 1976, pp. 70-85, y Monoson 2000, pp. 113-153.

${ }^{13}$ Véanse el testimonio de la Carta II y Monoson 2000, pp. 165-179.

${ }^{14} \mathrm{El}$ pasaje habitualmente citado como referencia es Eurípides, Troyanas, 1169. 


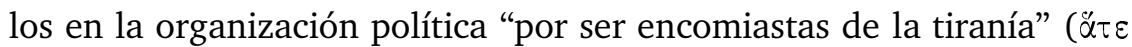

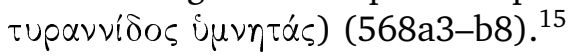

La poesía tradicional resulta así un medio de propaganda. Se describe su práctica diciendo que los poetas reúnen a multitudes y las persuaden y "arrastran a las ciudades hacia la tiranía y la democra-

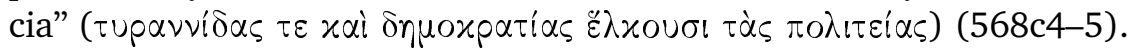
Esto es así porque el programa cultural que apoyan se basa en la poesía tradicional, mientras que las organizaciones políticas superiores son refractarias a esa práctica y los poetas se alejan de ellas "como si la falta

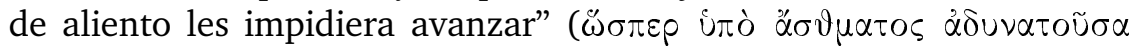
$\pi \circ \rho \varepsilon \cup ́ \varepsilon \sigma \vartheta \propto l) ~(568 d 2)$. Por lo tanto, el criterio para diferenciar al filósofo del tirano en los momentos iniciales de un proceso político es sobre todo el programa cultural que impulsa cada uno.

La asociación intrínseca entre la poesía y el biotipo tiránico se manifiesta en la descripción que abre el libro IX y se liga con el debilitamiento de la parte racional del alma, hasta el punto de que se equipara al fenómeno del sueño. La tiranía se parece a "cuando la parte del alma

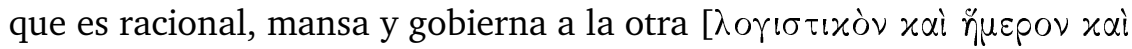

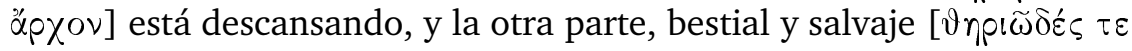
xai ăypıo ], llena de alimento y bebida aparta de sí el sueño, salta y tra-

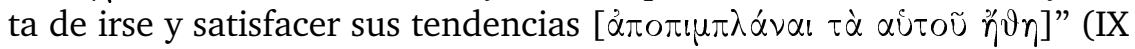
571c7). Sin importar su biotipo, el hombre en sueños no teme "intentar en su imaginación yacer con su madre y con cualquier otro de los hombres, dioses y animales, asesinar a quien sea y no abstenerse de ningún manjar" (IX 571c9-d2) y queda así a merced del sexo desenfrenado, la violencia y la gula. ${ }^{16}$ La retirada de la razón en el hombre tiránico libera lo onírico y lo torna real. Importa subrayar aquí que se trata del mismo material que abunda en los relatos tradicionales, empezando por los casos de Edipo y las historias de seducción de Zeus, junto con todo tipo de actos sangrientos hasta llegar a la antropofagia, como en el caso de Tiestes y otros relatos sobre canibalismo. ${ }^{17}$

En un contexto tiránico, se extrema el círculo vicioso de la ignorancia entre poesía y auditorio al que se refiere el símil de la bestia. En esta imagen, se retrata a los políticos y poetas tradicionales como sujetos que alimentan una bestia gigantesca y poderosa para aprender

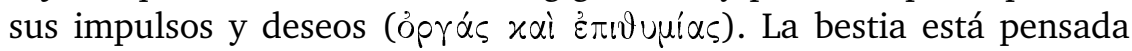

${ }^{15}$ Las traducciones son mías. Sigo la edición de J. Burnet en Oxford Classical Texts, salvo indicación en contrario.

${ }^{16}$ Véase, además, Rep. VIII $565 d$ y ss. y X 619c y ss.

${ }^{17}$ Sobre este último caso, véanse Hook 1992 y Detienne 1981, pp. 219 y ss.

Revista de Filosofía Diánoia, vol. 64, no. 83 (noviembre de 2019-abril de 2020) e-ISSN: 1870-4913 • DOI: https://doi.org/10.22201/iifs.18704913e.2019.83.1716 
con el modelo que se aplica al alma humana, de modo que los cuidados que se le deparan están orientados a dominar la parte inferior, que es la que orienta su conducta. Esta capacidad de dominar a la bestia recibe el nombre de sabiduría. ${ }^{18}$ Estos personajes confunden lo bueno con lo efectivo, es decir, con lo que calma a la bestia, haciendo de la sabiduría el "conocer el impulso y los gustos de la multifor-

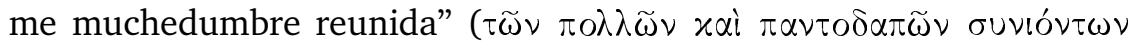

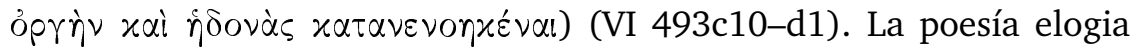
la tiranía y el poder la sostiene con sus favores en una alianza macabra entre amaestradores que aplacan al pueblo con dosis de miedo y sangre. Se trata del peor influjo de la poesía en la conformación anímica. En esta alianza se borra la diferencia entre ficción y realidad y los hombres tiránicos viven y mueren "como en la poesía", lejos de lo real.

Esta situación es la que explica la duplicidad que existe en el biotipo tiránico ya que, en rigor, por el principio general que sostiene a los regímenes políticos, una tiranía se mantiene en pie sólo si los hombres tiránicos son mayoritarios, pero no hay posibilidad, por el funcionamiento mismo de la tiranía, de que todos ellos tomen parte en el gobierno, sino a lo sumo unos pocos. El resto apoya este régimen porque le permite persistir en su vida disoluta sin preocuparse de reprimendas más que en el caso en que sus acciones colisionen con las de alguien más poderoso. Todas las consideraciones de Calicles en el Gorgias sobre el derecho del más fuerte se aplican a este caso. ${ }^{19} \mathrm{Al}$ identificar el mecanismo que desata este entramado, Platón señala hacia los placeres. El hombre de la tiranía vive en un entorno que alimenta sus deseos "llenos de incienso, mirra, coronas, vinos y placeres del tipo que surgen en estas compañías" (573a4-6) y los lleva al extremo hasta clavar "el aguijón del deseo" ( ción y frustración despierta irremediablemente la violencia propia de la tiranía que llega a parecerse a una locura (563b4-7), precisamente lo contrario de la razón característica del filósofo. ${ }^{20}$ Consideremos con mayor detalle qué hay detrás de esta asociación entre hedonismo y tiranía.

${ }^{18}$ Véanse Hitz 2011; Dorter 2006, pp. 174-175; Keyt 2006, pp. 193-195, y Weiss 2012, pp. 22-23.

${ }^{19}$ Véanse Gorgias 483a y ss. y Bravo 2016, pp. 317-334.

${ }^{20}$ No se aplica aquí la distinción entre tipos de locura que se encuentra en el Fedro 245c y ss., de la cual el tirano no participa en cuanto que no hay en él inspiración o creatividad, sino sólo desorden. Sobre locura y poesía, véase Schlesier 2006, pp. 45-60. 


\section{Quemaduras y toneles. Planteamientos anticirenaicos en el Gorgias}

El biotipo tiránico de la República responde a principios de hedonismo somático que coinciden con el modo en que Aristipo de Cirene comprendía la filosofía, aunque vista a través del cristal platónico. Esto permite sostener que el tirano platónico se describe de tal modo que su impugnación implica a la vez una crítica al modelo de hombre cirenaico. La conexión entre el Gorgias y Aristipo fue sugerida ya por Schleiermacher y ha sido reiterada desde entonces aunque con muy pocos detalles, lo cual propició dudas y rechazos igualmente generales. ${ }^{21}$ Por el contrario, los estudios con mayor detalle, como Irwin 1991 (pp. 55-82) y las discusiones que suscitó, se basan en los argumentos que permitirían a Aristipo escapar de las críticas al hedonismo que Platón plantea en el Gorgias más que en la lógica de la colisión teórica. Contamos, sin embargo, con elementos que permiten una exploración más profunda gracias a que existe una continuidad entre los exámenes de la República IX y el Gorgias. En efecto, en este último diálogo hay alusiones que vinculan el imaginario de los discípulos de Gorgias con el horizonte cirenaico, lo cual resulta una manera efectiva de asociar ambas líneas en una exégesis que puede ampliarse dentro del corpus. ${ }^{22}$

Consideremos dos casos que señalan la adecuación de esta lectura. En primer lugar, Platón usa contra Polo en 476c-d un argumento de cuño anticirenaico. En el contexto de discusión sobre si el castigo es un mal porque produce dolor y displacer, el Sócrates platónico sugiere un vínculo entre causa y efecto que permite inferir la primera a partir del segundo estableciendo que "si alguien hace una cosa, es necesario

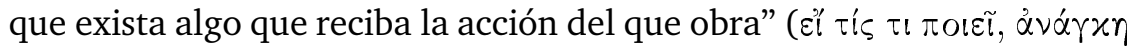

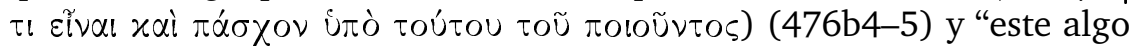
recibe lo que hace el que obra y del mismo modo que lo hace el que

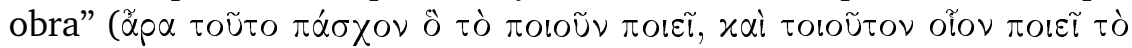

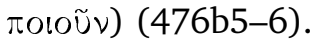

${ }^{21}$ El locus classicus de esta idea está en Schleiermacher 1836, p. 201. Véase además la rápida negativa de Kahn 1998, p. 17.

${ }^{22}$ Ha habido intentos de asociar el núcleo de la tesis cirenaica con desarrollos posteriores en la línea cirenaica asociados con Arete y Aristipo Metrodidacta; por ejemplo, en Tsouna 1998. He discutido esta cuestión en otro lado (Mársico 2013), por lo que, dado que no hay elementos concluyentes para suponer un desarrollo tardío y, por el contrario, las fuentes señalan como posteriores creencias que no se asocian a este espectro de ideas, supondré una cronología que habilita el diálogo con Platón y que además otorga un sentido pleno a los pasajes platónicos que analizo. 
Esto se apoya con dos ejemplos: "si lo que golpea da golpes violenta o rápidamente, ¿no es preciso que los reciba también del mismo modo

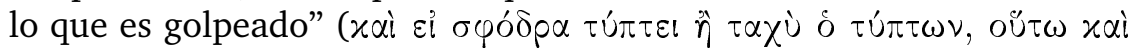

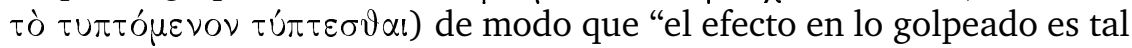

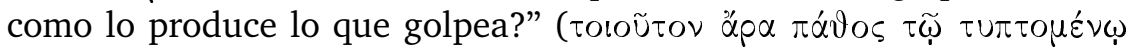

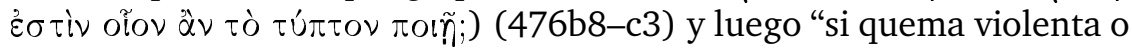
dolorosamente, ¿no es preciso que reciba la quemadura lo que es que-

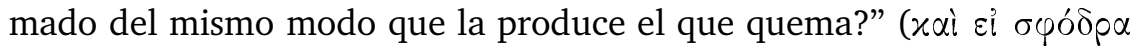

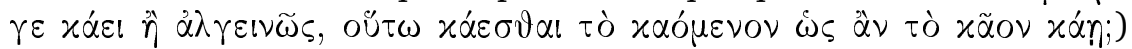
(476c4-6). Y "también si alguien corta, ¿no sucede lo mismo, que algo es cortado? [...] Y si la cortadura es grande, profunda o dolorosa, ¿lo

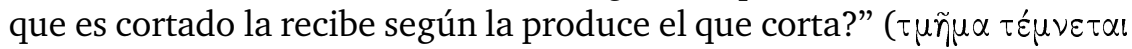

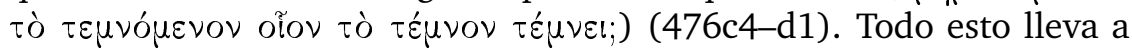
concluir que "tal como produce la acción lo que obra la sufre lo que la

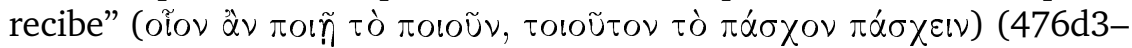
4), lo que sirve para indicar que, si el castigo se inflige justamente, este rasgo pasa al modo de recepción.

Este pasaje se ha considerado antecedente de los análisis gramaticales de la diátesis verbal, ${ }^{23}$ pero cabe notar que se trata además de un argumento de alto valor agónico en la medida en que se opone abiertamente a la metafísica indeterminista aristipiana, según la cual no se pueden hacer aseveraciones sobre el origen de las afecciones. ${ }^{24}$ En un testimonio importante sobre este asunto se afirma que los cirenaicos:

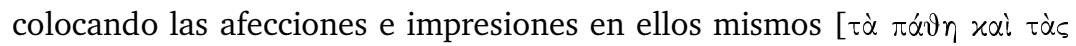

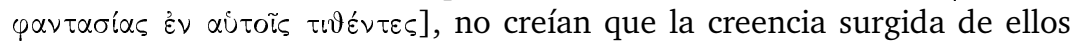
fuera suficiente para hacer afirmaciones sobre las cosas, sino que, como si estuvieran sitiados, abandonando lo exterior, se encerraron ellos mismos en las afecciones, sosteniendo sólo que "parece", pero sin pronunciarse

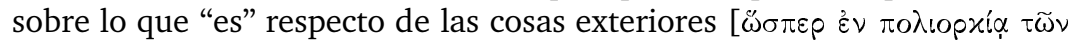

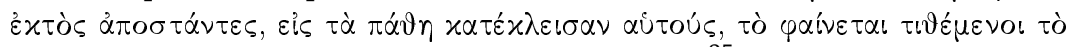

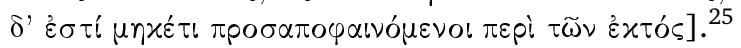

La propuesta cirenaica sostiene, entonces, que si se busca certeza se debe renunciar a la indagación ontológica del mundo, idea con la que

${ }^{23}$ Véanse Rijksbaron 1984, Bakker 1994 y Mársico 2007.

${ }^{24}$ No importa aquí el estatus del mundo, ya sea que tenga rasgos ontológicos que el sujeto no capta o que sean efectivamente indeterminados. Sobre esta discusión, continuación de la tesis de Irwin ya citada, véanse Tsouna 1998, O’Keefe 2015 y Zilioli 2015a.

${ }^{25}$ Plutarco, Contra Colotes, 24.1120c-d; SSR, IV A.211; FS, 632.

Revista de Filosofía Diánoia, vol. 64, no. 83 (noviembre de 2019-abril de 2020) e-ISSN: 1870-4913 • DOI: https://doi.org/10.22201/iifs.18704913e.2019.83.1716 
coincide con la primera tesis del Tratado sobre el no ser de Gorgias. Toda exploración de este terreno está condenada a enfrentarse a complejidades que conducen a callejones sin salida e incluso, si se alcanzara algún resultado, sería absorbido por las oscuridades de los planos conexos gnoseológico y lingüístico. Por lo común, Aristipo se compara con Protágoras, pero los contactos que tiene con Gorgias son en varios puntos más significativos. ${ }^{26}$

No obstante, en lugar de una vía de salida que renuncie a la certeza y explore la retórica, Aristipo adopta los resultados del Tratado del no ser como incentivo para encontrar la apodicticidad por otra vía. No hace falta la investigación ontológica condenada de antemano al fracaso, sino que hay que buscar en la interioridad el dato incontrovertible de los $\pi \dot{\alpha} \vartheta \eta{ }^{27}$ Las afecciones, por cierto, tienen el rasgo de certidumbre que basta para oficiar como base de un sistema fundacionista. Tal certidumbre se alcanza suspendiendo metodológicamente las afirmaciones

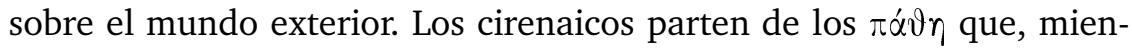
tras den cuenta exclusivamente de la afección, resultan seguros. Si, por el contrario, se proponen como afirmaciones sobre el mundo, pierden fundamento. La imagen del sitio es poderosa y retrata bien la condición para la certeza en un camino que anticipa las exploraciones cartesianas y fenomenológicas. ${ }^{28}$

La conexión entre el argumento platónico y la filosofía cirenaica se refuerza si se tienen en cuenta los testimonios que apelan a los ejemplos de golpes y quemaduras, como en el pasaje del Gorgias que mencioné. Por ejemplo:

Por eso los cirenaicos dicen que sólo las afecciones son aprehensibles, mientras que las cosas del exterior son inaprehensibles, pues aprehendo, dicen, que me quemo, pero que el fuego es lo que produce la quemadura

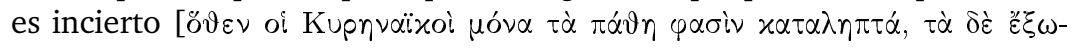

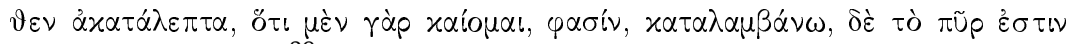

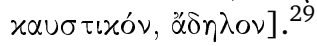

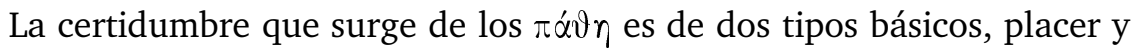
dolor, y en cada caso todo sujeto es capaz de reconocer sin duda posible si una afección pertenece a una u otra clase, aunque esto no se extiende

${ }^{26}$ Sobre Gorgias y Aristipo, véase Zilioli 2012, pp. 136-141.

${ }^{27}$ Tsouna 1998, pp. 31-41 y Mársico 2013, "Introducción”, secc. 4.2.

${ }^{28}$ Véase Inverso 2012, pp. 29-41.

${ }^{29}$ Comentario al Teeteto de Platón, Pap. Berlinense 9782, col. 65.18-39; SSR, IV A.214; FS, 635.

Revista de Filosofía Diánoia, vol. 64, no. 83 (noviembre de 2019-abril de 2020) e-ISSN: 1870-4913 • DOI: https://doi.org/10.22201/iifs.18704913e.2019.83.1716 
a sus causas aparentes en cuanto que implicarían un compromiso con afirmaciones ontológicas.

Es interesante notar que la utilización del ejemplo de la afección de quemazón reaparece en un contexto que apunta a caracterizar los alcances de la filosofía cirenaica:

Ese Aristipo, vistiéndose de púrpura, untándose perfumes, no era menos sensato que Diógenes, pues como alguien hubiese tomado coraje, creo, para ofrecer su cuerpo al Etna, si hubiese dispuesto el poder del cuerpo para que no fuera ultrajado por el fuego, así también quien lo preparó contra el placer, no se calienta estando en esas circunstancias, ni se quema, ni se derrite. ${ }^{30}$

Los ejemplos sobre la imposibilidad de hacer afirmaciones acerca del origen de un páthos son, en este testimonio de Máximo de Tiro, un ejemplo extremo de la desconexión entre el sujeto y su entorno. El mundo podría ser tal que ejerza su acción causal sobre el sujeto, pero si éste

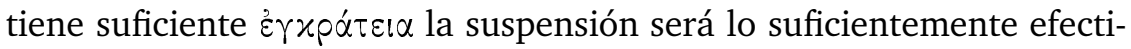
va como para que los efectos disruptores asociados con el placer no se produzcan, de modo tal que, podríamos decir, el fuego no quemará al hombre cirenaico. Si esto es así, la conexión necesaria que vislumbra Platón no es aceptada por los hedonistas, que pueden responder con la imagen del sitio.

En efecto, la situación de sitio permite que los cirenaicos se desentiendan por completo del entorno y mantengan el control de su dominio subjetivo. Esto explica que busquen placer y lo disfruten sin quedar atados a las "tentaciones", las cuales los llevarían a efectos no deseados de pérdida de control, ya que su repliegue implica la potestad interior para decidir sobre las propias acciones con un mundo reducido sin poder efectivo para actuar. La negativa cirenaica al compromiso ontológico permite adoptar esta variante que enfatiza la prioridad del plano subjetivo.

La respuesta platónica a esta posición se desentiende de las objeciones escépticas y es taxativa: si siento que soy golpeado, hay algo que golpea, y si siento que soy quemado, hay algo que quema, de modo que cualquier suspensión del juicio es de una sutileza innecesaria y

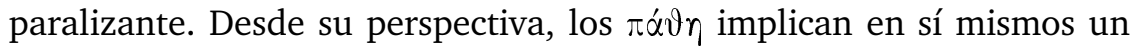
compromiso ontológico y no escapan, por lo tanto, al esquema de relación entre la realidad, el pensamiento y el lenguaje de cuño parme-

${ }^{30}$ Máximo de Tiro, Disertaciones filosóficas, I.9; SSR, IV A.58; FS, 449. 
nídeo. ${ }^{31}$ Si así no fuese, los cirenaicos podrían realmente fundamentar una posición hedonista.

Esto nos lleva al segundo caso de cuestionamiento de la filosofía cirenaica en el Gorgias que me interesa mostrar. Según vimos, en el terreno cirenaico la suspensión metodológica de las afirmaciones sobre el mundo es necesaria para justificar el principio del hedonismo se-

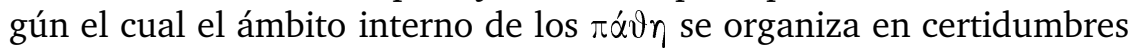
de placer y dolor, con una tendencia natural a perseguir lo primero y evitar lo segundo. Sin salir de la propia experiencia y tropezar con las aporías de la realidad, el conocimiento y el lenguaje que entorpecen en el platonismo el acceso al mundo y el ascenso a las Formas, Aristipo encuentra un espacio de apodicticidad a la mano que señala hacia el placer como dato primario. Ese corolario es justo el que se ridiculiza en el Gorgias asociándolo al más bestial de los interlocutores, Calicles.

En 492c este interlocutor sostiene su posición frente a los embates de Sócrates cuando dice que "todas esas otras fantasías y convenciones de los hombres contrarias a la naturaleza son necedades y cosas sin va-

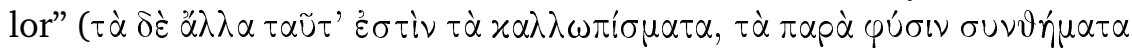

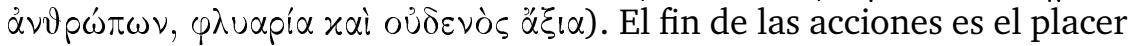
concebido como una tendencia natural "kinética", es decir, que implica un movimiento y, por lo tanto, no se han de reprimir los deseos so pena de creer que las piedras y los muertos podrían ser felices (492e5-6).

La respuesta platónica se esboza con el símil de los toneles, que se presenta en su forma preliminar como el caso de hombres que "llevarían agua al tonel agujereado con un cedazo igualmente agujerea-

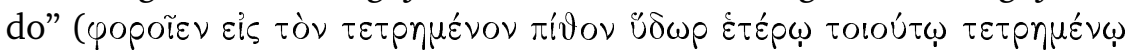

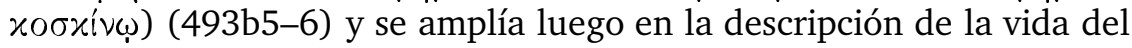
hombre de toneles sanos que "lograría quedarse tranquilo" ( $\dot{\eta} \sigma u \chi_{i} \alpha \nu$ है $\chi$ ol) (493e6), mientras que el de toneles podridos "se vería obligado a estarlos llenando constantemente día y noche, o soportaría los más gra-

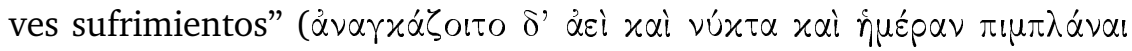

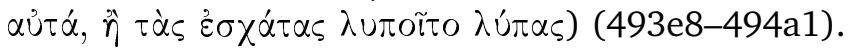

Desde esta perspectiva, el pasaje del símil de los toneles resulta ser un ejercicio de retórica anticirenaica: quien se rija por el placer es presa de las penurias del hombre del tonel agujereado y su destino de Sísifo. El enfrentamiento se completa con la comparación entre el hedonista y el sarnoso, en la que Calicles debería aceptar que "tener sarna, rascarse, con la posibilidad de rascarse cuanto se quiera, y pasar la vida rascán-

\footnotetext{
${ }^{31}$ Sobre la tríada realidad, pensamiento y lenguaje, véanse Scolnicov 2000 y Mársico 2005.
} 
dose es vivir felizmente" (493d). ${ }^{32}$ Como corolario se sostiene que el hombre cirenaico, con su asociación entre placer y kínesis, está enfermo aunque crea que persigue lo natural, y la aplicación inmoderada de este modelo lleva de manera directa a la sed de poder de Calicles y su legitimación de cualquier tipo de violencia para complacer las ansias personales que no se pueden satisfacer. Calicles describe al hombre tiránico que, de multiplicarse en la democracia, produce un cambio de régimen político. Como en la República, también en el Gorgias la poesía está en la base de este proceso, como se sugiere en $502 \mathrm{~b}$, donde se la retrata como una práctica cuyo completo propósito es agradar a los espectadores y alimentar, por lo tanto, sus parámetros hedonistas. ${ }^{33}$

\section{El símil del ascensor}

Retornemos al ámbito de la República. Si el Gorgias retrata al hombre cirenaico como esclavo de la consecución de placeres, por su parte, la República IX se explaya en los efectos que tendría la difusión masiva de este biotipo en la comunidad. Si los habitantes eligen en forma mayoritaria el placer instantáneo, el resultado sería la llegada al poder del tirano y el sueño hedonista resulta, como vimos, una pesadilla corporizada. El gobernante insatisfecho no se detiene hasta tomar decisiones brutales que comprometen el bienestar y la vida de sus conciudadanos, enredados todos en los juegos de odio y poder que rigen la ciudad tiránica.

La crítica al hedonismo y a la poesía que conviene a una impugnación de la línea cirenaica constituye el elemento principal del símil del ascensor. En IX 586a1-c5 se intenta probar, como respuesta a las dudas de los inicios del libro II y a las consideraciones sobre el símil de los metales en III 414b1-415d5 respecto de la felicidad de los guardianes y filósofos, que a través de la vida teórica es en efecto posible alcanzar esta meta con mayor plenitud que en otros casos. Para ello se echa mano de un esquema de tres niveles similar, aunque no idéntico, al del símil de la línea y el pasaje sobre la mímesis en la República X 595a1608b8. Allí se describe una suerte de ascensor con tres estancias, una más baja caracterizada por el displacer, otra intermedia y una superior donde se accede a placeres intelectuales. Así:

Los inexpertos en sensatez y perfección que se la pasan siempre en festines y cosas por el estilo son transportados hacia abajo, según parece, y

${ }^{32}$ Véase Inverso 2010.

${ }^{33}$ Véase Prat 1993, p. 151.

Revista de Filosofía Diánoia, vol. 64, no. 83 (noviembre de 2019-abril de 2020) e-ISSN: 1870-4913 • DOI: https://doi.org/10.22201/iifs.18704913e.2019.83.1716 
nuevamente hacia lo intermedio y en ese tránsito vagan por la vida [oi àp $\alpha$

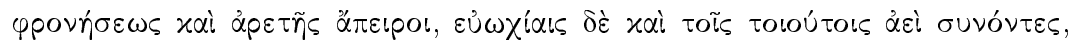

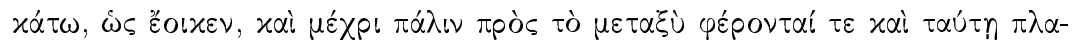
$\nu \widetilde{\omega} \nu \tau \alpha \iota$ oì $\beta i ́ o u] . ~(586 a 1-3)$

Los dos niveles inferiores corresponden al plano de lo sensible, mientras que el superior implica el contacto con las Formas propio del placer intelectual. De acuerdo con este símil, los hedonistas oscilan entre los dos niveles del plano sensible yendo del placer al dolor, razón por la cual miden todo con base en esta oposición, cuyos términos se comprenden como afecciones somáticas. La idea es compatible con las nociones cirenaicas y explica asimismo la afirmación de Calicles en el Gorgias 492e acerca de que, sin el movimiento de búsqueda del placer, adviene una felicidad propia de muertos y piedras. En efecto, si sólo hay placer y dolor sensible, su suspensión implica una suerte de ausencia vital que reñiría con la vida.

El símil del ascensor es en este punto un complemento del símil de los toneles y una continuación de la argumentación anticirenaica porque agrega de manera explícita la referencia a un tipo de placer que éstos no han categorizado. Se trata de un placer positivo que explicita la naturaleza del "placer tranquilo" mencionado en el Gorgias 493e. Por lo tanto, esta $\dot{\eta} \sigma u \chi^{i} \alpha$ no constituye una suspensión, sino un ascenso a un

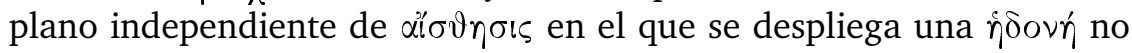
somática. De esta forma, para Platón los hedonistas "jamás marcharon más allá de eso elevando la mirada hacia el verdadero arriba, ni se colmaron en verdad con lo real, ni probaron el placer sólido y puro" (586a4-5); es decir, que su compromiso materialista los ata al placer sensible.

Así, esclavizados en este espectro "por la ambición de estas cosas se matan unos a otros a patadas y cornadas con cuernos y pezuñas de

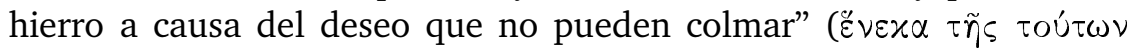

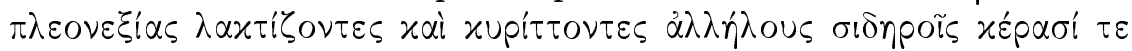

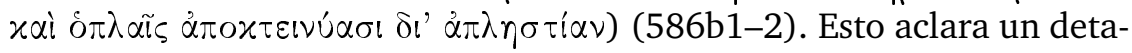
lle importante del comportamiento biotípico. El tirano no es un monstruo aislado, sino que la insatisfacción de los deseos conlleva violencia, ejercida de modo generalizado entre todos los individuos del biotipo tiránico. En efecto, uno o algunos llegan a detentar el poder y a legitimar el régimen de violencia porque la mayoría la practica en forma horizontal en la comunidad. El símil del ascensor cifra la explicación de esta conducta en que "no colman con placeres reales ni su parte real ni

Revista de Filosofía Diánoia, vol. 64, no. 83 (noviembre de 2019-abril de 2020) e-ISSN: 1870-4913 • DOI: https://doi.org/10.22201/iifs.18704913e.2019.83.1716 


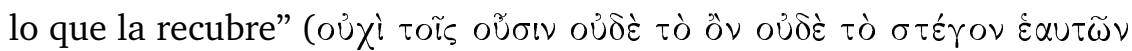
$\pi \mu \mu \pi \lambda \dot{\alpha} \nu \tau \varepsilon \varsigma)(586 \mathrm{~b} 3-4)$.

Esta consideración antropológica coincide con los planos en juego: no logran satisfacer ni lo más real, el alma (es decir, aquello que, de acuerdo con la caracterización del Fedón 79b, es lo más afín a las Formas) ni lo que la recubre, el cuerpo. ${ }^{34} \mathrm{Al}$ contrario, el filósofo como prototipo del modelo platónico accede al plano inteligible y tiene a la mano un tipo de placeres estables que confieren verdadera eudaimonía. Los hombres de la aristocracia no pueden todos alcanzar este tipo de prácticas, pero el programa cultural que sostienen señala con claridad que esta práctica es posible y es la que legitima el acceso al gobierno. En las antípodas, atrapados en los niveles del dominio somático, los hedonistas ignoran que hay una alternativa a la kínesis somática permanente. Es obvio que jamás aceptarían los postulados de la Teoría de las Formas, pero eso no es un problema para Platón, quien se dirige a interlocutores que deben elegir entre el modelo cirenaico, peligroso porque promete placer, y el suyo.

El desafío es mayúsculo, como se puede inferir de la respuesta de Glaucón, quien no duda en considerar este pasaje una descripción de la vida de la multitud. Tras aceptar la asociación, Sócrates ofrece una respuesta que nos devuelve al terreno de la poesía. Allí se refiere a los "placeres mezclados con dolores" y su estatus comparable a "imágenes y pinturas sombreadas" en comparación con el verdadero placer. El placer sensible es una copia degradada del placer asociado con el plano inteligible, de modo que en algún sentido el filósofo es quien practica el verdadero hedonismo. Al desviar la atención de ese nivel, la poesía conspira contra el placer real y hace que los insensatos "engendren

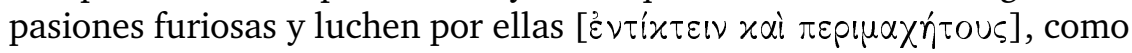
dice Estesícoro que lucharon en Troya por la imagen de Helena, porque ignoraban la verdad" (586c3-6).

La poesía vuelve a aparecer como un elemento complementario del hedonismo. Así como en el Gorgias 502b era un instrumento de la vida tiránica, aquí se señala un caso de mímesis debilitada que alimenta los deseos inferiores justo para impedir la captación del plano superior de placer que pondría en evidencia la escasez de las variantes sensibles. La analogía que sirve para retratar esta situación surge de una referencia a la poesía. Se cuenta que Estesícoro se volvió ciego por haber criticado a Helena, pero que, luego de hacer una palinodia o discurso de

\footnotetext{
${ }^{34}$ Esta caracterización ya se enuncia en $585 \mathrm{~d}$. El término stégon que se utiliza para referirse a lo que recubre el alma conjuga la idea de refugio con la de tumba o receptáculo. Sobre este asunto, véase Hale 1969.
}

Revista de Filosofía Diánoia, vol. 64, no. 83 (noviembre de 2019-abril de 2020) e-ISSN: 1870-4913 • DOI: https://doi.org/10.22201/iifs.18704913e.2019.83.1716 
retractación, referido por Platón también en su Fedro 243a, recobró la vista. La nueva versión decía que Paris no había sido acompañado por la Helena real y la guerra no se luchó por ella, sino por un fantasma suyo hecho por los dioses. ${ }^{35}$

Así como la poesía tradicional homérica ofrece parámetros sin anclaje en lo real, del mismo modo las multitudes obnubiladas por el hedonismo (que sería desde esta perspectiva una suerte de filosofía de sentido común) están atrapadas en una farsa mimética que los obliga a pelear por fantasmas, a extenuarse en la búsqueda de placeres sin alcanzar nunca la paz. Por lo tanto, la tiranía es la faz política de esta disposición anímica cuyo alimento principal es la construcción simbólica de la poesía. Por ello resulta imprescindible en el terreno platónico avanzar en una redefinición de un programa político cultural ajeno a la agenda hedonista que rompa con la clausura en los niveles inferiores y sirva como "ascensor" para que más individuos tengan claro que existen placeres inteligibles. Sólo así se pone freno al crecimiento de las tendencias tiránicas que terminan por tomarlo todo.

\section{El número del tirano}

La distancia entre el modelo filosófico y el modelo tiránico se subraya en el pasaje sobre el número del tirano. Está claro a estas alturas que la insatisfacción que se asocia con el hedonismo produce infelicidad, pero se sugiere en este pasaje que la diferencia con la felicidad que alcanza el filósofo es extrema. Esto, como he dicho, es de una importancia fundamental en la polémica contra la filosofía cirenaica porque Platón se enfrenta a un adversario que ofrece una doctrina que se aprende fácilmente y promete rendimientos en términos de bienestar inmensos, en especial si se lo compara con la esforzada vida del filósofo platónico.

Esta diferencia entre el gobernante filósofo platónico y el tirano se extiende al nivel biotípico, ya que, como dije, la mayoría de los individuos de la tiranía no llega a los crímenes y a la insatisfacción del gobernante de ese régimen, sino a una versión morigerada de ellas, del mismo modo que los habitantes de la aristocracia no alcanzan las Formas y la felicidad asociada, pero se pueden acercar a ella y gozar de los beneficios de una ciudad guiada por esos ideales. Para ilustrar esta idea, Platón retoma una modalidad que utiliza también en el pasaje del número nupcial, en la República VIII $546 .{ }^{36}$ Allí se señala la dificultad

${ }^{35}$ Véanse Heródoto, II 112-120, y Eurípides, Helena, passim.

${ }^{36}$ Sobre el número nupcial, véanse Adam 1902, ad loc.; Gaiser 1974; Ehrhardt

Revista de Filosofía Diánoia, vol. 64, no. 83 (noviembre de 2019-abril de 2020) e-ISSN: 1870-4913 • DOI: https://doi.org/10.22201/iifs.18704913e.2019.83.1716 
de elegir el momento propicio para que los guardianes engendren hijos que resistan a las tendencias timocráticas. La complejidad de los cálculos da idea de la dificultad y, en cierto modo, de una batalla perdida de antemano. En el caso del número del tirano, el número creciente de las cifras en juego señala una diferencia cuantiosa entre las veces que un filósofo es más feliz que un tirano.

El cálculo permite concluir por medio de multiplicaciones con base tres que el filósofo es setecientas veintinueve veces más feliz que el tirano. Para ello se establece que el tirano está alejado en tres grados del oligarca, pues en medio de ellos está el demócrata, de modo que "cohabitaría con una apariencia del placer que está a tres grados del oligarca

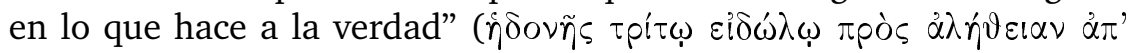

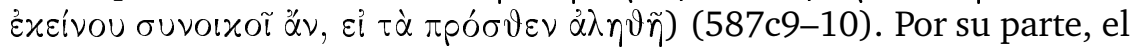
hombre del biotipo oligárquico está en tercer lugar respecto del filósofo, por lo cual "el tirano está alejado del placer verdadero en un número

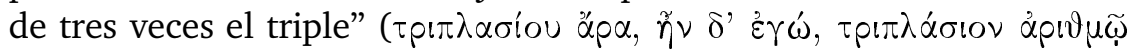

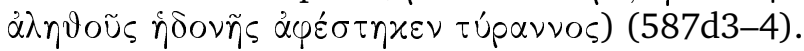

Respecto de esto se dice que "la apariencia del placer tiránico podría ser una cifra de superficie, según la cifra de su dimensión" (

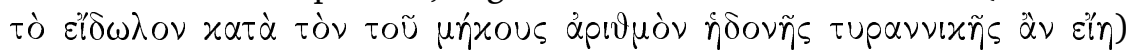
(587d6-7), interpretando esta referencia con las operaciones de elevar al cuadrado y al cubo, por lo cual, si se pretende expresar la medida en que ser filósofo es ventajoso:

descubrirá que como resultado de la multiplicación, éste vive setecientas veintinueve veces más placenteramente, mientras que el tirano es el más

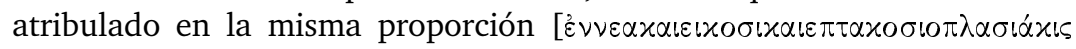

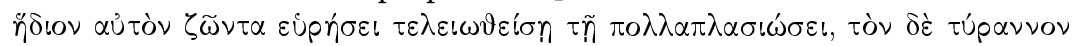

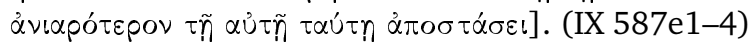

En su reconstrucción más razonable, el pasaje se refiere a una cifra de superficie o plana en la medida en que se determina por el tamaño de los lados de su figura $(3 \times 3=9)$. Inmediatamente se afirma que la distancia se determina elevando la cantidad de placeres al exponente dos, es decir, a la potencia que corresponde a esta cifra de superficie, y luego al cubo, pues después de ver que el placer del tirano se aleja 9 veces del placer del oligarca, para saber cuánto dista finalmente el placer del tirano del placer real debe observarse cuántos lugares se aleja, a su vez, el oligarca del rey, que resultan de nuevo 3 lugares, ya que

1986 y Jacovides y McNamee 2003. Sobre la interpretación de Marsilio Ficino, véase Allen 1994.

Revista de Filosofía Diánoia, vol. 64, no. 83 (noviembre de 2019-abril de 2020) e-ISSN: 1870-4913 • DOI: https://doi.org/10.22201/iifs.18704913e.2019.83.1716 
entre ellos está el timócrata, por lo cual resulta que habrá que elevar al cubo el resultado anterior $(9 \times 9 \times 9)$ y, así, es posible concluir que el rey vive 729 veces más feliz que el tirano. ${ }^{37}$

La cifra tres habilita un razonamiento con aires pitagóricos, entre cuyas doctrinas resulta conocido el procedimiento de potenciación en la cual el número 729 tenía funciones especiales. Filolao, por ejemplo, propuso un ciclo calendárico de 729 meses, probablemente basándose en que ese número es el cuadrado de 27 , número de la luna, y el cubo de 9 , número de la tierra. 9 es además múltiplo de 3 , número que se considera un elemento básico. La relación entre 3, 9, 27 y 279 reaparece en el Sobre la arquitectura de Vitruvio, que diseña su obra sobre un total de 729 versos, divididos en diez partes - la década-, cada una de las cuales tiene un número de versos múltiplo de 3 .

En rigor, el cálculo de Platón tiene algo de caprichoso, ya que en realidad el cálculo podría basarse simplemente en la diferencia de 5 lugares que hay entre el tirano y el rey (rey 1 , timócrata 2 , oligarca 3 , demócrata 4, tirano 5). Hay quienes han explicado la posición del tirano por la intención de Platón de introducir grados intermedios de degradación del placer (el demócrata y el tirano tienen dos placeres inauténticos y uno auténtico), mientras que la elevación a la potencia obedece a su intención de mostrar que el alejamiento del placer del rey se hace de manera creciente y no homogénea. De este modo, explican que el placer del timócrata es 8 veces menor que el del rey, el del oligarca es 27 veces menor, etc. ${ }^{38}$ Creo que hay una explicación mejor para este pasaje.

El interlocutor de Sócrates en 588a interpreta el cálculo de modo lúdico, lo cual no necesariamente significa falta de seriedad, sino, al contrario, una reacción a la referencia irónica respecto de otra posición teórica. La referencia intertextual que subyace en todo el análisis de la tiranía, como he sugerido, es la cirenaica, por lo cual el número del tirano puede estar dirigido contra esta línea. La razonabilidad de esta idea puede mostrarse en el hecho de que esta insistencia en el número tres presenta un parecido llamativo con un testimonio que Epifanio, un teórico cristiano del siglo IV que combate las herejías posteriores al Concilio de Nicea, atribuye a Aristipo. Afirma Epifanio:

Aristipo de Cirene: dado que era glotón y amante del placer, dijo que el fin es el placer del alma. Quien siente placer es feliz, y quien no siente placer enteramente es tres veces infeliz y desdichado, según dice [oữos

${ }^{37}$ Sobre el número del tirano, véanse Gibson 1955, Brumbaugh 1988 y McClung 1983.

${ }^{38}$ Véanse Reeve 2004, p. 291, y Dorter 2006, p. 299.

Revista de Filosofía Diánoia, vol. 64, no. 83 (noviembre de 2019-abril de 2020) e-ISSN: 1870-4913 • DOI: https://doi.org/10.22201/iifs.18704913e.2019.83.1716 


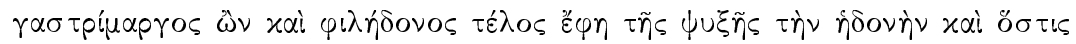

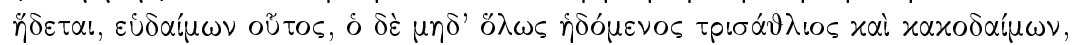
$\left.\ddot{\omega} \varphi_{\eta} \sigma \mathrm{l}\right] .{ }^{39}$

Es preciso notar los puntos de contacto entre los dos textos: Aristipo, el defensor de la concepción del placer como movimiento y primariamente somático establece una proporción enfática, en la que "tres veces" puede equivaler a un superlativo. El hombre que no goza del placer somático es el colmo de la infelicidad. Al criticar esta posición, Platón parece recurrir a la misma idea sólo para elevar la apuesta y convertir este "tres veces" en un "triplemente triple". Con esto la proporción se vuelve un complemento plástico del símil del ascensor: si desde la perspectiva aristipiana quien no siente placer es tres veces infeliz, desde la perspectiva platónica quien está atrapado en la dialéctica del placer somático a la manera del hedonista cirenaico y no advierte el nivel superior al que accede el filósofo se pierde la posibilidad de ser no sólo "tres veces" más feliz, sino "setecientas veintinueve". El superlativo aristipiano se ve superado hasta la exacerbación. Por lo tanto, el planteamiento en la República IX puede entenderse no sólo como un intento de ligar la figura del filósofo con una vida feliz y placentera, sino a la vez como una impugnación de la posición cirenaica.

Puede aducirse incluso un pasaje adicional vinculado con este tema, pues las diferencias entre el platonismo y la línea cirenaica se plasman también en el juicio que le merecen las matemáticas. Mientras Platón las considera fundamentales y sugiere a menudo que constituyen un modelo para el planteamiento de las Formas, Aristipo las rechazaba por inútiles. Una crítica de Aristóteles a Aristipo sostiene lo siguiente:

De modo que por eso algunos de los sofistas, por ejemplo Aristipo, enlodaron a las matemáticas, pues en las demás técnicas, incluso en las manuales, por ejemplo la albañilería y la zapatería, respecto de todo se dice "porque es mejor o peor", mientras que las matemáticas no hacen ningún

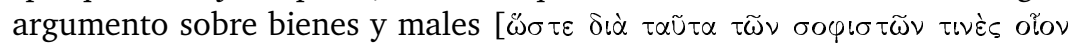

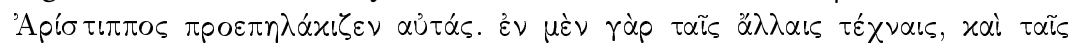

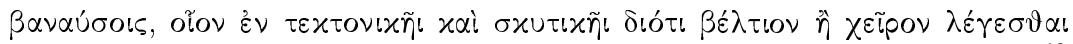

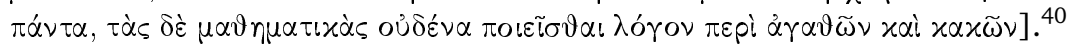

${ }^{39}$ Epifanio, Contra todas las herejías, II 29 (III 23); FS, 596; SSR, IV A.177.

${ }^{40}$ Aristóteles, Metafísica, III.2 996a32-996b1 (FS, 581; SSR, IV A.170). 
En la tradición posterior la misma idea se atribuye a Aristipo en una forma radical: "si todo lo que existe actúa en vistas de lo bueno o lo bello, sin embargo, las matemáticas no apuntan ni a lo bello ni a lo bueno,

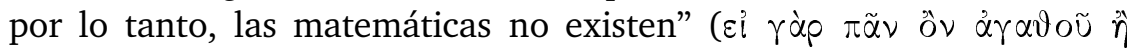

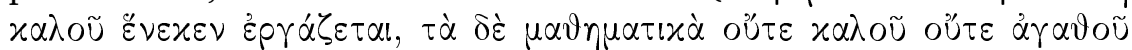

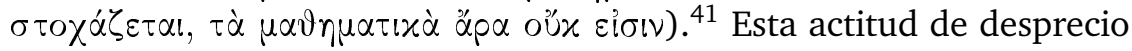
se repite como un rasgo de Calicles en el Gorgias: en 508a se atribuye su posición íntegra a su descuido de la geometría, cosa que lo hace inclinarse por la ambición, que resulta, desde esta perspectiva, en una proporción alterada. El meollo del desvío de Calicles responde a la adopción de una tesis cirenaica cuyo error se advierte por el número del tirano en un despliegue geométrico-matemático explícito.

Si es así, la apelación de Platón a las matemáticas para construir el corolario de un argumento anticirenaico echando mano de una mención numérica de Aristipo es un buen ejemplo de ironía. Para quien decoró la puerta de entrada de la Academia con el mensaje de exclusi-

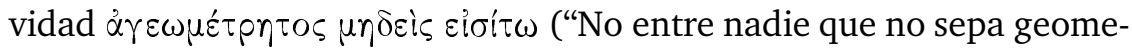
tría"), este desprecio era un nuevo elemento para tomar distancia, que justificaba probablemente que las teorías hedonistas de los cirenaicos se hundieran bajo una montaña de números.

\section{Corolarios}

El estudio de los pasajes en los que puede inferirse un vínculo intertextual entre las obras de Platón y los cirenaicos ofrece elementos para evaluar esta relación saliendo de las temáticas analizadas hasta el momento a propósito de la noción de placer y su anclaje metafísico. La consideración del horizonte de la filosofía práctica, y en especial sus ideas sobre el programa político, el lugar que le cabe a la poesía tradicional, así como su descripción y evaluación de la tiranía y sus relaciones con otros regímenes de gobierno, presenta vínculos relevantes con la línea aristipiana y permite repensar pasajes muy transitados de la obra de Platón.

La concurrencia de vínculos que unen los argumentos de la quemadura y el símil de los toneles en el Gorgias con el símil del ascensor y el número del tirano en la República como parte de un dispositivo anticirenaico en la obra de Platón invita a examinar los textos fundamentales de la época clásica desde una perspectiva que contemple la dimensión

${ }^{41}$ Alejandro, Sobre la Metafísica de Aristóteles, 739.21-24 (FS, 587; SSR, IV A.171).

Revista de Filosofía Diánoia, vol. 64, no. 83 (noviembre de 2019-abril de 2020) e-ISSN: 1870-4913 • DOI: https://doi.org/10.22201/iifs.18704913e.2019.83.1716 
agónica en que fueron compuestos. El resultado es un horizonte enriquecido en el que los orígenes de la filosofía como género discursivo autónomo muestran un entramado dialógico de numerosas teorías y sistemas que funcionaron como incentivo recíproco y traban con la historia posterior de la disciplina vínculos que ofrecen una infinidad de nuevos desafíos exegéticos.

\section{BIBLIOGRAFÍA}

Adam, J. (ed.), 1902, The Republic of Plato, Cambridge University Press, Cambridge.

Allen, D., 2010, Why Plato Wrote. Blackwell Bristol Lectures on Greece, Rome and the Classical Tradition, Wiley-Blackwell, Chichester.

Allen, M., 1994, Nuptial Arithmetic. Marsilio Ficino's Commentary on the Fatal Number in Book VIII of Plato's Republic, University of California Press, Berkeley.

Andersen, P., 1994, Empirical Studies in Diathesis, Nodus, Münster.

Bakker, E., 1994, "Voice, Aspect and Aktionsart. Middle and Passive in Ancient Greek", en B.A. Fox y P.J. Hopper (comps.), Voice. Form and Function, Benjamins, Ámsterdam, pp. 23-47.

Boesche, R., 2010, Theories of Tyranny, Penn State University, Pennsylvania.

Bravo, F., 2016, "Who Is Plato's Callicles and What Does He Teach?", en G. Cornelli, Plato's Styles and Characters. Between Literature and Philosophy, De Gruyter, Berlín, pp. 317-334.

Brumbaugh, R., 1988, "The Mathematical Imagery of Plato, Republic X", Teaching Philosophy, vol. 7, no. 3, pp. 59-63.

Brunschwig, J., 2001, "La théorie cyrénaïque de la connaissance et le problème de ses rapports avec Socrate", en G. Romeyer-Dherbey y J. Gourinat (comps.), Socrate et les socratiques, Vrin, París, pp. 457-477.

Cawkwell, G.L., 1995, "Early Greek Tyranny and the People", Classical Quarterly, vol. 45 no. 1 , pp. 73-86.

Cerri, G., 1991, Platone sociologo della comunicazione, Il Saggiatore, Milán.

Clerk Shaw, J., 2015, Plato's Anti-Hedonism and the Protagoras, Cambridge University Press, Cambridge.

Detienne, M., 1981, L'invention de la mythologie, Gallimard, París.

Divenosa, M. y C. Mársico, 2005, Platón. República, Losada, Buenos Aires.

Dorter, K., 2006, The Transformation of Plato's Republic, Lexington, Lanham, Maryland.

Ehrenberg, V., 1969, The Greek State, Routledge, Londres.

Ehrhardt, E., 1986, "The Word of the Muses (Plato, Rep. 8.546)", Classical Quarterly, vol. 36, no. 2, pp. 407-420.

Ferrari, G., 2005, City and Soul in Plato's Republic, University of Chicago Press, Chicago.

Fraser, P., 1972, Ptolemaic Alexandria, Oxford University Press, Oxford.

Revista de Filosofía Diánoia, vol. 64, no. 83 (noviembre de 2019-abril de 2020) e-ISSN: 1870-4913 • DOI: https://doi.org/10.22201/iifs.18704913e.2019.83.1716 
Gaiser, K., 1974, "Die Rede der Musen über der Grund von Ordnung und Unordnung: Platons Politeia 545d-547a", en K. Döring y W. Kullmann (comps.), Studia Platonica. Festschrift für H. Grundert, Grüner, Ámsterdam, pp. 49-85.

__ 1984, Platone come scrittore filosofico: saggi sull'ermeneutica dei dialoghi platonici, Bibliopolis, Nápoles.

Giannantoni, G., 1958, I cirenaici: raccolta delle fonti antiche, Sansoni, Florencia.

_ 1990, Socratis et Socraticorum Reliquiae (SSR), Bibliopolis, Nápoles.

Gibson, A., 1955, "Plato's Mathematical Imagination", The Review of Metaphysics, vol. 9, no. 1, pp. 57-70.

Gray, V., 2007, Xenophon. On Government, Cambridge University Press, Cambridge.

Hale, S., 1969, "Possible Pythagorean Influences on Plato's Views of Physical Education in the Republic", Research Quarterly. American Association for Health, Physical Education and Recreation, vol. 40, no. 4, pp. 692-699.

Halliwell, S., 2011, "Antidotes and Incantations: Is There a Cure for Poetry in Plato's Republic?", en P. Destrée y F.-G. Herrmann (comps.), Plato and the Poets, Brill, Leiden, pp. 241-266. DoI: 10.1163/ej.9789004201293.i434.60.

Hitz, Z., 2011, "Degenerate Regimes in Plato's Republic", en M. McPherran (comp.), Plato's Republic. A Critical Guide, Cambridge University Press, Cambridge.

Hook, B., 1992, Tyranny and Cannibalism, Duke University, Duke.

Hunter, R., 2012, Plato and the Traditions of Ancient Literature. The Silent Stream, Cambridge University Press, Cambridge.

Illarraga, R., 2014, "Platón contemporáneo en el debate sobre el liberalismo: entreguerras, Karl Popper y Slavoj Žižek", en E. Bieda y C. Mársico (comps.), Diálogos interepocales. La Antigüedad griega en el pensamiento contemporáneo, Rhesis, Buenos Aires.

Illarraga, R., C. Mársico y P. Marzocca, 2017, Jenofonte/Pseudo-Jenofonte. Constitución de los lacedemonios, Constitución de los atenienses y Hierón, Universidad Nacional de Quilmes/Prometeo, Buenos Aires.

Inverso, H., 2010, "Elementos para la reconstrucción de una retórica cirenaica", en A. Poratti (comp.), La(s) retórica(s) en la Antigüedad y sus proyecciones, Universidad Nacional de Rosario, Rosario.

—, 2012 , "Las epochaí escéptica y cirenaica consideradas desde la tradición fenomenológica", La Lámpara de Diógenes, vol. 13, no. 24, pp. 29-41.

Irwin, T., 1991, "Aristippus against Happiness", The Monist, vol. 74, no. 1, pp. $55-82$.

Jacovides, M. y K. McNamee, 2003, "Annotations to the Speech of the Muses (Plat. Rep. 546b-c)", Zeitschrift für Papyrologie und Epigraphik, vol. 144, pp. 31-50.

Kahn, C., 1998, Plato and the Socratic Dialogue. The Philosophical Use of a Literary Form, Cambridge University Press, Cambridge.

Revista de Filosofía Diánoia, vol. 64, no. 83 (noviembre de 2019-abril de 2020) e-ISSN: 1870-4913 • DOI: https://doi.org/10.22201/iifs.18704913e.2019.83.1716 
Keyt, D., 2006, "Plato and the Ship of State", en G. Santas (comp.), The Blackwell Guide to Plato's Republic, Blackwell, Londres, pp. 189-213.

Klosko, G., 1996, "Popper's Plato: An Assessment", Philosophy of the Social Sciences, vol. 26, no. 4, pp. 509-527.

Lampe, K., 2014, "Review of U. Zilioli, The Cyrenaics, Durham, Acumen", Classical Review, vol. 64, no. 1, pp. 54-56.

_ 2015, The Birth of Hedonism. The Cyrenaic Philosophers and Pleasure as a Way of Life, Princeton University Press, Princeton.

Levy, R., 1956, Plato in Sicily, Faber, Londres.

Mársico, C., 1998, "Poesía y origen del discurso filosófico en la República de Platón", Pomoerium, vol. 3, pp. 51-60.

__ 2005, El surgimiento de la gramática en Occidente. De la dialéctica a la téchne grammatiké, Diss, Buenos Aires.

__ 2007, Polémicas y paradigmas en la invención de la gramática, Ediciones del Copista, Córdoba.

——, 2013, Filósofos socráticos (FS), Testimonios y fragmentos. I. Megáricos y Cirenaicos, Losada, Buenos Aires.

_ 2019, "Las opiniones del gran animal. Exploraciones sobre el programa de política cultural en la República a la luz de las discusiones entre Platón y Antístenes", en E. Bieda y C. Mársico (comps.), Ética, política y estética en el pensamiento griego, Biblos, Buenos Aires, pp. 205-226.

- 2020, "Beyond Burning Pleasure: On the Development of the Central Tenets of the Cyrenaic Philosophy", Philosophie Antique, no. 20.

McClung, W., 1983, The Architecture of Paradise: Survivals of Eden and Jerusalem, University of California Press, Los Ángeles.

McGlew, J., 1993, Tyranny and Political Culture in Ancient Greece, Cornell University Press, Ithaca/Londres.

Monoson, S., 2000, Plato's Democratic Entanglements. Athenian Politics and the Practice of Philosophy, Princeton University Press, Princeton.

Nightingale, A., 1995, Genres in Dialogue, Cambridge University Press, Cambridge.

Niquist, M., 2013, Arbitrary Rule. Slavery, Tyranny, and Power of Life and Death, University of Chicago Press, Chicago.

O'Keefe, T., 2015, "The Sources and Scope of Cyrenaic Scepticism", en Zilioli 2015b, pp. 99-113.

Parker, V., 1998, "Túpavvos. The Semantics of a Political Concept from Archilochus to Aristotle", Hermes, vol. 126, no. 2, pp. 145-172.

Platón, Platonis opera, Clarendon, Oxford.

Pratt, L., 1993, Lying and Poetry from Homer to Pindar. Falsehood and Deception in Archaic Greek Poetics, University of Michigan Press, Michigan.

Raaflaub, K., 2004, The Discovery of Freedom in Ancient Greece, University of Chicago Press, Chicago.

Reeve, C., 2004, Plato. Republic, Hackett, Nueva York.

Riginos, A., 1976, Platonica, Brill, Leiden.

Revista de Filosofía Diánoia, vol. 64, no. 83 (noviembre de 2019-abril de 2020) e-ISSN: 1870-4913 • DOI: https://doi.org/10.22201/iifs.18704913e.2019.83.1716 
Rijksbaron, A., 1984, The Syntax and Semantics of the Verb in Classical Greek, Gieben, Ámsterdam.

Rosenstock, B., 1994, “Athena's Cloak. Plato's Critique of the Democratic City in the Republic", Political Theory, vol. 22, no. 3, pp. 363-390.

Rowe, C., 2007, Plato and the Art of Philosophical Writing, Cambridge University Press, Cambridge.

—, 2015 , "The First-Generation Socratics and the Socratic Schools. The Case of the Cyrenaics", en Zilioli 2015b, pp. 26-42.

Schleiermacher, F., 1836, Introductions to the Dialogues of Plato, trad. W. Dobson, Deighton, Londres.

Schlesier, R., 2006, "Platons Erfindung des Wahnsinnigen Dichters. Ektasie und Enthusiasmus als poetisch-religiöse Erfahrung", Zeitschrift für Ästhetik und Allgemeine Kunstwissenschaft, vol. 51, no. 1, pp. 46-61.

Scolnicov, S., 2000, "Euthydemus' Philosophy of Language", en T. Robinson y L. Brisson (comps.), Plato. Euthydemus, Lysis, Charmides. Proceedings of the V Symposium Platonicum, Academia, Sankt Augustin, pp. 115-122.

Taylor, A., 1926, Plato. The Man and His Work, Routledge, Londres.

Tsouna, V., 1998, The Epistemology of the Cyrenaic School, University of California Press, Santa Bárbara.

Vegetti, M., 1999, Guida alla lettura della Repubblica di Platone, Laterza, Bari. —, 2006, Platone. Repubblica VI (libri VIII-IX), Bibliopolis, Nápoles.

Walsh, W., 1962, "Plato and the Philosophy of History. History and Theory in the Republic", History and Theory, vol. 2, no. 1, pp. 3-16.

Weiss, R., 2012, Plato's Two Paradigms, Cornell University Press, Ithaca.

Zilioli, U., 2012, The Cyrenaics, Acumen, Londres.

—_, 2015a, "The Cyrenaics as Metaphysical Indeterminists", en Zilioli 2015b, pp. 114-133.

Zilioli, U. (comp.), 2015b, From the Socratics to the Socratic Schools: Classical Ethics, Metaphysics and Epistemology, Routledge, Londres.

Recibido el 9 de junio de 2018; revisado el 8 de abril de 2019; aceptado el 11 de agosto de 2019. 